\title{
Pesquisa
}

\section{SÍNDROME DE BURNOUT EM FUNCIONÁRIOS DE UMA EMPRESA DE ELETRIFICAÇÃO EM JUAZEIRO DO NORTE}

\author{
Glauco Valério Pinheiro Andrade (1) \\ Maria Glauciane Lima Eduardo Rocha (2) \\ Pl[inio Pinto Malveira (3) \\ Josefa Janiele Lopes Moreira (4)
}

\begin{abstract}
Resumo
A Síndrome de burnout é considerada como um dos principais indicadores de bem-estar subjetivo, sendo avaliada como uma medida geral ou como referência a áreas importantes da vida, a exemplo do trabalho e da família. Este estudo discute a compreensão da Síndrome de Burnout em funcionários de uma empresa de Eletrificação em Juazeiro do Norte, Ceará. Para a coleta de dados utilizou-se o Inventário de Burnout de Maslash, uma escala de 7 pontos, variando de 0 (nunca) a 6 (todo dia), e uma entrevista semi-estruturada contendo informações sóciodemográficas. Os resultados demonstraram índices preocupantes no nível de despersonalização alto $(8,7 \%)$ e baixo Envolvimento Pessoal no Trabalho em 2,9\% da amostra. Portanto, 11,6\% dos funcionários em fase de alerta, fase bem considerável da síndrome de burnout, porém passível de tratamento.
\end{abstract}

Palavras-chave: Síndrome de burnout, Estresse, Ambiente laboral

\section{Introdução}

As novas maneiras de se estruturar os processos de trabalho, as novas tecnologias disponibilizadas às empresas, e todo conhecimento hoje disponível sobre as doenças ocupacionais, ainda não foram eficazes em fornecer estratégias para minimizar a problemática. 
A própria medicina demorou a se aperceber sobre os efeitos do ambiente laboral para a saúde mental dos trabalhadores, incluindo-se aí as relações nele existentes.

Segundo Dejours (1992), o final do século XX foi uma importante referência para os estudos relacionados a qualidade de vida laboral. À partir de então, passou-se a cobrar uma medicina mais voltada para o trabalho, com foco na saúde dos trabalhadores. Os aspectos ergonômicos, tais como ruídos, iluminação, anatomicidade do mobiliário, exposição a agentes de risco (biológicos, físicos, químicos, elétricos, condições de higiene e segurança de uma maneira geral).

Ainda por essa época, segundo Dejours (1992), o fortalecimento sindical propõe novas medidas preventivas, agora no sentido mental e emocional. Situações de ameaça à saúde mental do trabalhador, ampliando as possibilidades de resguardo à saúde, antes voltadas mais aos aspectos físicos e fisiológicos.

As pesquisas na área da psicopatologia se multiplicaram, comprovando que a atividade laboral influencia, não somente na produtividade, mas na auto-estima, no Bem-Estar Subjetivo e na Qualidade de Vida Emocional, dentre outras dimensões do homem. Desta forma, tomando ponto de destaque na produção de reações e sintomas associados (ALEVATO, 1999).

A Psicologia do trabalho toma forma como resultado de pesquisas que culminam na necessidade da inclusão de enfermidades psicossomáticas, psicológicas e psíquicas, no âmbito das doenças ocupacionais. Dessa maneira, evolui a idéia de que, não somente a maneira de trabalhar, mas as implicações dos relacionamentos interpessoais, do exercício das chefias e dos comportamentos grupais e suas diversas possibilidades, trariam implicações na saúde mental do trabalhador (ALEVATO (1999).

Autores como De Masi (1999) considera que a automação e a robotização da produção, bem como a velocidade das informações e decisões, possibilitadas pela informática, tendem a uma transformação do mundo, onde, países mais ricos ditarão as formas de trabalho, certamente com maior robotização das tarefas e menores ofertas de trabalho não intelectualizado, gerando o que o mesmo denomina de "ócio criativo cultural".

No Brasil, diversos estudos se preocuparam com aspectos relacionados ao Estresse e a Síndrome de Burnout, principalmente através dos trabalhos de Marilda Lipp (1984) e BenevidesPereira (2002). A atenção aos aspectos da Prevenção psicológica relacional passaram a merecer certo destaque, até por conta globalização da economia e suas repercussões.

A Lei 8.213/91, através do decreto 3.048/99, reconhece as doenças ocupacionais, dentre elas a depressão, a hipertensão, o Estresse, a Síndrome de burnout e outras, que possam ser comprovadas junto a Previdência Social, como associadas ao tipo de trabalho desenvolvido. (BRASIL, 1999)

O Código de Identificação de Doenças (CID-10), passa acontemplar também um capítulo específico sob o título: "Transtornos Mentais e do Comportamento Relacionados com o Trabalho", 
enfocando as patologias e sua manifestações comportamentais associadas, tais como alcoolismo, drogadicção, comportamento suicida, dentre outros (OMS, 1997).

Uma pesquisa de Domenich (2002) revelou que o Brasil vem ocupando posição destacada quando o assunto envolve estresse ocupacional. Este estudo envolveu países como Estados Unidos, Alemanha, França, Brasil, Israel, Japão, China, Hong Kong e Fiji, e demonstrou-se que o Brasil ocupa o segundo lugar em número de trabalhadores com "Síndrome de Burnout". Entre os brasileiros, observou-se que $70 \%$ são afetados pelo Estresse ocupacional e 30\% do total estão vitimados pela "Síndrome de Burnout". No Japão estes números se elevam, chegando a $85 \%$ dos trabalhadores com estresse crônico e 70\% com manifestação da "Síndrome de Burnout".

Pelo exposto, considera-se a necessidade de se estudar constantemente, a Síndrome de burnout, nas diversas esferas laborais, de maneira a poder identificar suas causas e criar estratégias de enfrentamento cada vez mais eficazes.

\section{O Estresse no ambiente de trabalho}

"Stress" é uma palavra derivada do latim, significando ao longo do tempo "adversidade" ou "aflição" (século XVII), evoluindo posteriormente para significar "força", "pressão" ou "esforço" (final do Século XVIII). Só no início do século XX despertou nos estudiosos maior interesse dos seus efeitos na saúde física e mental das pessoas (RODRIGUES, 1997).

Um dos primeiros estudiosos a transpor o conceito de "stress" da física para a saúde foi Hans Selye (1959), conceituando-o como qualquer adaptação requerida à pessoa, frente a uma situação de perigo iminente. Trata-se de uma metáfora associada ao grau de deformidade que uma estrutura sofre quando é submetida a um esforço. Selye descreveu os sintomas do estresse como Síndrome Geral de Adaptação, composto de três fases sucessivas; alarme, resistência e esgotamento. Após a fase de esgotamento era observado o surgimento de diversas doenças sérias, como úlcera, hipertensão arterial, artrites e lesões miocárdicas. Esta definição apresenta o stress como um agente neutro, capaz de tornar-se positivo ou negativo de acordo com a percepção e a interpretação de cada pessoa.

No Brasil, o nome sofreu adaptação, sendo possível as duas nomenclaturas, Stress ou Estresse.

O estresse positivo, chamado de eustresse, assim como o negativo, chamado de distresse, causam reações fisiológicas similares: as extremidades (mãos e pés) tendem a ficar suados e frios, a aceleração cardíaca e pressão arterial tendem a subir, o nível de tensão muscular tende a aumentar, etc. No nível emocional, no entanto, as reações ao "stress" são bastante diferentes. O eustresse motiva e estimula a pessoa a lidar com a situação. Ao contrário, o distresse acovarda o indivíduo, fazendo com que se intimide e fuja da situação, já que representa um conjunto de relações que o organismo 
desenvolve ao ser submetido a uma situação que exige esforço de adaptação (RODRIGUES E GASPARINI, 1992).

\section{A Síndrome de Burnout}

A Síndrome de Burnout, diz respeito a um tipo de estresse particular, que acomete pessoas que trabalhaam com pessoas. É conhecida como a Síndrome do Esgotamento Profissional, estudado ecomo fenômeno psicológico por Herbert Freudenberger em 1974. Posteriormente a Psicóloga Christina Maslach, interessa-se pelo tema e desenvolve uma medida para a síndrome. Trata-se do Inventory Maslach Burnout, que investiga a influência da carga emocional do trabalho no comportamento dos profissionais que lidam com relações humanas durante sua jornada laboral.

Esta síndrome foi observada, inicialmente, em profissões relacionadas a um contato interpessoal mais exigente, tais como médicos, psicanalistas, carcereiros, assistentes sociais, comerciários, professores, advogados, atendentes públicos, enfermeiros, funcionários de departamento pessoal, telemarketing e bombeiros (CARLOTTO, 2004).

$\mathrm{Na}$ atualidade as observações já se estendem a todos os profissionais que interagem de forma ativa com pessoas, que cuidam e/ou solucionam problemas de outras pessoas, que obedecem a técnicas e métodos complexos, fazendo parte de organizações de trabalho submetidas a avaliações.

Burnout foi largamente difundido como uma síndrome psicológica, decorrente da tensão emocional crônica. Esta síndrome é o resultado do estresse emocional incrementado na interação com outras pessoas. Difere do estresse genérico e geralmente incorpora sentimentos de fracasso. Seus principais indicadores são: exaustão emocional, despersonalização e diminuição de realização pessoal:

- Exaustão emocional - sentimentos de fadiga e esgotamento energético emocional - reflete o aspecto de estresse individual;

- Despersonalização - atitudes negativas de dureza e de distanciamento excessivo dos profissionais em relação às pessoas beneficiárias dos seus serviços - representa o aspecto interpessoal.

- Diminuição da realização pessoal - associada ao sentimento de incompetência à percepção de um desempenho insatisfatório no trabalho - retrata o aspecto de auto-avaliação (CODO E VASQUESMENEZES, 2000).

Defensores desta síndrome como sendo diferente do estresse, alegam que esta doença envolve atitudes e condutas negativas com relação aos usuários, clientes, organização e trabalho, enquanto o estresse apareceria mais como um esgotamento pessoal com interferência na vida do sujeito e não necessariamente na sua relação com o trabalho.Porém, pode ser compreendida como a consequiência mais depressiva do estresse desencadeado pelo trabalho. 


\section{Método}

A pesquisa foi realizada com o intuito de conhecer a saúde emocional dos funcionários da Coelce-Juazeiro do Norte, empresa do ramo de eletrificação, através do Inventário de Burnout de Maslach (MBI). Esta pesquisa se constitui num substrato de informações que representa, potencialmente, valioso subsídio para qualquer iniciativa de impacto e intervenção junto a essa população específica.

Trata-se de um estudo, fundamentalmente quantitativo, realizado no período de agosto a setembro de 2011.

A coleta de dados foi realizada no período de agosto a setembro de 2011. A amostra foi de conveniência, uma vez que contou apenas com a participação daqueles que se dispuseram a responder. A abordagem constou da aplicação de questionário estruturado, contendo dois blocos de perguntas que procuravam conhecer os seguintes aspectos: (1) Síndrome de Burnout; (2) Características sóciodemográficas.

1 - Inventário de Burnout de Maslash $\mathrm{O}$ instrumento mais utilizado para avaliar burnout, independentemente das características ocupacionais da amostra e de sua origem, segundo Gil-Monte e Peiró (1999), é o MBI - Maslach Burnout Inventory, elaborado por Christina Maslach e Susan Jackson em 1978. Sua construção partiu de duas dimensões, exaustão emocional e despersonalização, sendo que a terceira dimensão, realização profissional, surgiu após estudo desenvolvido com centenas de pessoas de uma ampla gama de profissionais (MASLACH, 1993).

O MBI avalia como o trabalhador vivencia seu trabalho, de acordo com três dimensões conceituais: exaustão emocional, realização profissional e despersonalização. É um instrumento utilizado exclusivamente para a avaliação da síndrome, não levando em consideração os elementos antecedentes e as consequiências de seu processo. Ele avalia índices de burnout de acordo com os escores de cada dimensão, sendo que altos escores em exaustão emocional e despersonalização e baixos escores em realização profissional (esta subescala é inversa) indicam alto nível de burnout (MASLACH E JACKSON, 1986). Gil-Monte e Peiró (1997) reforçam a importância de avaliar o MBI como um construto tridimensional, ou seja, as três dimensões devem ser avaliadas e consideradas, a fim de manter sua perspectiva de síndrome.

Nesse estudo, o MBI (Maslach Burnout Inventory), é direcionado aos funcionários, para mensurar a frequência com que indivíduo experimenta sentimentos típicos do_burnout. Consta de 16 itens, sendo 5 de Exaustão emocional (EE); 5 de Despersonalização e 6 de Envolvimento Pessoal no Trabalho (EPT), sendo respondido através de uma escala do tipo Likert de 7 pontos. A escala neste estudo vai de " $0=$ nunca" a " $6=$ todo dia" .

2 - Características Sócio-Demográficas. Tiveram o objetivo de demonstrar um perfil da amostra, envolvendo questões tais como: Sexo, Idade, profissão, tempo em que trabalha na empresa, Religião, Renda média, dentre outras . 
Com relação à análise dos dados, foi utilizada estatísticas descritivas e de tomada de decisão, através do Pacote estatístico SPSS (Statistical Package for the Social Sciences), versão 11,5. A margem de erro deste estudo é de até cinco pontos percentuais, para mais ou para menos, com intervalo de confiança de 95\%. O erro amostral, que identifica quanto os resultados de uma pesquisa podem variar foi de $5 \%$ e mostra que os percentuais de respostas obtidas (também chamados de "frequiências") podem variar para mais $5 \%$ ou menos $5 \%$.

O presente estudo atendeu às determinações da Resolução 196/96 que trata sobre a ética na experimentação com seres humanos.

\section{Resultados}

Fizeram parte deste estudo 35 funcionários da Companhia de Eletrificação Coelce, localizada no Centro do Município de Juazeiro do Norte, que não se opuseram à participação. Suas idades variaram entre 19 a 53 anos (média 33,9. $\mathrm{Dp}=11,21$ ), a maioria do sexo masculino $(65,7 \%)$ contra $34,3 \%$ do sexo feminino, que trabalham em média há 10 anos na empresa $(\mathrm{Dp}=10,44)$.

A seguir, a distribuição de frequiência relacionada à Profissão dos funcionários entrevistados, e outras questões relacionadas, a saber:

Tabela 1: Distribuição da profissão dos sujeitos da pesquisa

\begin{tabular}{lcc}
\hline Profissão & Freqüência & Percentual \\
\hline Aux. Administrativo & 12 & 34,2 \\
\hline Eletrotécnico & 10 & 28,6 \\
\hline Eletricista & 5 & 14,2 \\
\hline Engenheiro & 3 & 8,6 \\
\hline Estagiário & 2 & 5,7 \\
\hline Aux. De Manutenção & 1 & 2,9 \\
\hline Atendente & 1 & 2,9 \\
\hline Não respondeu & $\mathbf{3 5}$ & $\mathbf{1 0 0 , 0}$ \\
\hline Total & Freqüência & Percentual \\
\hline Se faz o que gosta no ambiente de trabalho & 01 & 2,9 \\
\hline Não & 34 & 97,1 \\
\hline Sim & $\mathbf{3 5}$ & $\mathbf{1 0 0 , 0}$ \\
\hline Total & Freqüîncia & Percentual \\
\hline Se pudesse mudaria de profissão & 20 & 57,1 \\
\hline Sim & & \\
\hline
\end{tabular}




\begin{tabular}{lcccc}
\hline Não & \multicolumn{2}{c}{14} & 40,0 \\
\hline Não respondeu & \multicolumn{3}{c}{1} & 2,9 \\
\hline Total & \multicolumn{3}{c}{$\mathbf{3 5}$} & $\mathbf{1 0 0 , 0}$ \\
\hline Continua... & Mínimo & Máximo & Média & Desvio padrão \\
\hline & 19 & 53 & 33,97 & 11,21 \\
\hline Idade & 300,00 & $4.300,00$ & $1.521,87$ & 1030,13 \\
\hline Renda mensal & 450,00 & $7.000,00$ & $2.401,58$ & 1622,06 \\
\hline Renda que acredita justa & 0 & 29 & 10,77 & 10,77 \\
\hline $\begin{array}{l}\text { Número de anos em que } \\
\text { trabalham na empresa }\end{array}$ & & & & \\
\hline
\end{tabular}

Juazeiro do Norte - CE, 2011.

Quanto à profissão, a amostra variou da seguinte forma: Auxiliares administrativos (34\%), Eletrotécnicos (28,6\%), Eletricistas (14,2\%), Engenheiros (8,6\%), Estagiários (5,7\%), Auxiliar de manutenção (2,9\%), Atendente (2,9\%) e uma pessoa não respondeu $(2,9 \%)$.

Dentre estes, apenas uma pessoa não faz o que gosta no ambiente de trabalho (2,9\%), os outros $97,1 \%$ afirmam fazerem o que gosta no ambiente laboral. Apesar disso, 57,1\% afirmou que, se pudesse, mudaria de profissão.

Com relação à Renda mensal atual, esta variou de $\mathrm{R} \$ 300,00$, no caso dos estagiários, até $\mathrm{R} \$$ 4.300,00, sendo a Renda mensal média $\mathrm{R} \$ 1.512,87$ ( $\mathrm{Dp}=1030,13)$. Os respondentes revelaram também a Renda que acreditam justa ao trabalho que executam. Esta variou de $\mathrm{R} \$ 450,00$ até $\mathrm{R} \$$ $7.000,00$, sendo a média igual a $\mathrm{R} \$ 2.401,58(\mathrm{Dp}=1.622,06)$, portanto pelo menos $50 \%$ a mais do que percebem atualmente.

Outro aspecto importante a ser considerado foi a religião, cujos resultados encontram-se disposto na tabela abaixo.

Tabela 2: Religião dos sujeitos da amostra

\begin{tabular}{lcc}
\hline & Freqüência & Percentual \\
\hline Católica & 27 & 77,1 \\
\hline Evangélica & 4 & 11,4 \\
\hline Agnóstico & 3 & 8,6 \\
\hline Não respondeu & 1 & 2,9 \\
\hline Total & $\mathbf{3 5}$ & $\mathbf{1 0 0 , 0}$ \\
\hline
\end{tabular}

Juazeiro do Norte - CE, 2011. 
Neste aspecto os respondentes se auto denominaram como Católicos $(77,1 \%)$, Evangélicos $(11,4 \%)$, Agnósticos, ou sem religião definida $(8,6 \%)$ e apenas uma pessoa não respondeu a esta pergunta $(2,9 \%)$. Neste caso, uma grande parcela parece engajada com os preceitos de alguma religião $(88,5 \%)$.

A Religião tem sido considerada por diversos autores (FORMIGA, 2005; PETRAITIS, FLAY e MILLER, 1995; TAMAYO, NICARETTA, RIBEIRO e BARBOSA, 1995), como uma medida protetiva em relação aos comportamentos delitivos e/ou anti-sociais. A religião parece orientar as pessoas a aderirem às normas sociais e aos valores morais como fator de proteção dos eventos que podem ser desencadeados em caso de uma desestruturação por estresse laboral.

Assim, investir em programas de intervenção entre os funcionários ajudando-os a refletirem os valores normativos e sociais, seria bem provável uma reelaboração de determinadas situações conflituosas, quem sabe, levando a inibição de uma tendência desviante dos padrões convencionais da sociedade, bem como, a manutenção de sua saúde psicológica e social.

Quanto aos motivos de estarem exercendo esta profissão, estes revelaram-se em duas categorias, segundo a tabela 3: Motivos positivos, como: Gostar do que faz (48,5\%), Aprimorar conhecimentos $(11,4 \%)$, Concluiu curso na área $(11,4 \%)$ e Condição financeira favorável $(8,6 \%)$. Com relação aos Motivos negativos, os respondentes relataram: Comodismo/conveniência $(11,4 \%)$, Para pagar a faculdade $(2,9 \%)$, Não teve outra oportunidade $(2,9 \%)$ e Por necessidade financeira $(2,9 \%)$. Portanto, 79,9\% dos respondentes exercem a função por motivos positivos. É possível que, fazer o que se gosta, seja uma pré-condição que atenua a possibilidade do estresse laboral. No caso em questão, há que se preocupar com um contingente de $20,1 \%$ dos funcionários que não estão fazendo o que gostam no ambiente de trabalho. Estes certamente estarão propensos a desenvolverem sintomatologias reativas ao estresse gerado pelas tarefas percebidas como não agradáveis.

Tabela 3: Motivos para estar exercendo a profissão atual

\begin{tabular}{lcc}
\hline Motivos positivos & Freqüência & Percentual \\
\hline Gostar do que faz & 17 & 48,5 \\
\hline Aprimorar conhecimentos & 4 & 11,4 \\
\hline Concluiu curso na área & 4 & 11,4 \\
\hline Condição financeira favorável & 3 & 8,6 \\
\hline Motivos Negativos & Freqüiência & Percentual \\
\hline Comodismo/Conveniência & 4 & 11,4 \\
\hline Para pagar a faculdade & 1 & 2,9 \\
\hline Não teve outra oportunidade & 1 & 2,9 \\
\hline Por necessidade financeira & 1 & 2,9 \\
\hline
\end{tabular}


Juazeiro do Norte - CE, 2011.

Com relação ao que causa estresse no trabalho, os respondentes eliciaram quatro categorias, a saber:

Categoria 1 - Problemas Pessoais, com dezesseis (16) eliciações: Pressão das chefias (8); Algumas pessoas (2); Clientes ignorantes (2); Falta de compreensão; Falta de compromisso; Falta de conhecimento; Trabalho em equipe.

Categoria 2 - Problemas de Processo de trabalho, com seis (6) eliciações: Carga de trabalho em excesso (2); Coisas que não se resolvem; Pedir algo via terceiros; Reuniões; Tarefas não cumpridas.

Categoria 3 - problemas de Material, com três (3) eliciações: A parte financeira incompativel; As dificuldades materiais; A falta de recursos.

Categoria 4 - Problemas de Estrutura, com três (3) eliciações: Desorganização (2); Barulho, Sistema não funciona.

Dejours, (1992, p.128), afirma que "a organização do trabalho, fixada externamente pelas chefias, pode, em certos casos, entrar em confronto com o compromisso operatório favorável, que o trabalhador teria instituído espontaneamente". E continua, “A organização do trabalho, neste sentido, pode comprometer imediatamente o equilíbrio psicossomático.' “... O autor prossegue na mesma linha de raciocínio, "A organização do trabalho é causa de uma fragilização somática, na medida em que ela pode bloquear os esforços do trabalhador para adequar o modo operatório às necessidades de sua estrutura mental".

Silva (2000), a seu turno, ressalta que o stress ocupacional tem ocasionado diversos fatores de absenteísmo e elevados custos às empresas e, ainda, muitas enfermidades de natureza psicossomáticas. Assinala que o stress decorre da inadequação relacional entre a organização do trabalho e o homem. A ruptura do fluxo de interação homem-trabalho trás conseqüências gravíssimas. Ressalta, ainda, que a Síndrome de Burnout é o processo de agudização do estresse ocupacional crônico, uma espécie de resposta ao stress laboral, descrevendo sintomas que se evidenciam pela decepção e perda de interesse pela atividade de trabalho que surge nas profissões que trabalham em contato direto com pessoas em prestação de serviço como conseqüência desse contato diário no seu trabalho.

A diferenciação entre o stress ocupacional crônico e a Síndrome tem sido apontada pelos autores mediante o surgimento de fadiga emocional, física e mental, sentimentos de impotência e inutilidade, falta de entusiasmo pelo trabalho, pela vida em geral e baixa auto-estima. 
No caso da empresa em questão, os funcionários revelaram diversas situações causadoras de estresse, em diversas dimensões, que ainda precisam ser enfrentadas pela direção, evitando-se assim um maior comprometimento a saúde mental dos mesmos.

Com relação a forma como lida com o estresse, os respondentes eliciaram duas categorias, a saber:

Categoria 1 - Positiva, isto é, demonstraram uma forma de lidar com o estresse de maneira resiliente, isto é, a vivência foi percebida como uma contribuição a saúde emocional, na medida em que, parecem lidar com o estresse de forma potencializadora de um estado desafiante, que os motiva à resolução do problema.

As falas correspondentes a esta categoria foram as seguintes: Concentração; corrigindo os erros; com criatividade; paciência (3); Descansa; encara com naturalidade; faz o serviço; organiza prioridades; proatividade; procura ajudar os colegas; procura algo para fazer; Resolve dentro das possibilidades (2); respira fundo; se acalma; tenta atender às solicitações; Trabalha da melhor maneira possível.

Categoria 2 - Negativa, isto é, os sujeitos parecem responderem às situações estressantes com um aumento de tensão, respondendo muitas vezes de maneira inadequada, elevando assim o sofrimento psíquico. As respostas foram as seguintes: Sente que há um gasto de energia; Ignora; Com irritação, estresse, atrasa as coisas; com jogo de cintura; tenta manter o controle; Não se envolvendo; com receio; reuniões estressantes; imprime um ritmo mais acelerado (4).

Observa-se que alguns respondentes encontraram uma forma resiliente de lidar com o estresse, enquanto que outros, apresentam como consequências do estresse laboral, uma série de sintomatologias que tendem a comprometer tanto a sua saúde emocional, quanto suas relações interpessoais e o seu trabalho.

Com relação aos índices de Síndrome de Burnout, os resultados estão dispostos na tabela 4, a seguir.

Tabela 4: Síndrome de Burnout nos funcionários da amostra

\begin{tabular}{lccc}
\hline Nível de Burnout & Baixo & Médio & Alto \\
\hline Exaustão Emocional & $94,2 \%$ & $5,8 \%$ & - \\
\hline Despersonalização & $71,2 \%$ & $20,1 \%$ & $\underline{\mathbf{8 , 7 \%}}$ \\
\hline Envolvimento Pessoal no Trabalho & $\underline{\mathbf{2 , 9 \%}}$ & $51,4 \%$ & $45,7 \%$ \\
\hline
\end{tabular}

Juazeiro do Norte, 2012 
Com relação a Síndrome de Burnout entre os sujeitos da pesquisa, constatou-se os seguintes resultados: Exaustão emocional - 94,2\% no nível baixo e 5,8\% no nível médio; Despersonalização $71,2 \%$ no nível baixo; 20,1\% no nível médio e 8,7\% no nível alto; Envolvimento pessoal no trabalho 2,9\% no nível baixo; $51,4 \%$ no nível médio e 45,7\% no nível alto. Isso, considerando as médias adotadas pelo Gepeb - Grupo de Estudos e Pesquisas sobre Estresse e Burnout (BENEVIDESPEREIRA, 2002), apresentadas também por Volpato et al. (2003) como valores-padrão das médias da população brasileira.

Estes dados demonstram que as possibilidades de desenvolvimento de síndrome de burnout, com esta amostra de funcionários, ainda é baixa. Mas há pelo menos quatro funcionários $(11,6 \%)$ em fase de alerta, no sentido de já demonstrarem sinais preocupantes. Este aspecto fica demonstrado tanto quando temos 2,9\% da amostra com um baixo nível de Envolvimento Pessoal no Trabalho (EPT) e, também um percentual de 8,7\% que já se encontra no nível de Despersonalização (DE) alto, uma fase bem considerável de burnout, porém passível de tratamento.

Silva (2000), citando França e Rodrigues, propõe a seguinte estratégia de prevenção à Síndrome de Burnout: “a) aumentar a variedade de rotinas, para evitar a monotonia; b) prevenir o excesso de horas extras; c) dar melhor suporte social às pessoas; d) melhorar as condições sociais e físicas de trabalho; e, e) investir no aperfeiçoamento profissional e pessoal dos trabalhadores.

\section{Conclusão}

Os resultados observados corroboram estudos de Benevides-Pereira (2002) e Campos (2005), os quais sugerem que um indivíduo revela síndrome de burnout quando apresenta altos níveis de Exaustão Emocional (EE) e/ou Despersonalização (DE) e baixo nível de reduzida Realização Profissional (RP).

Desta forma, pode-se pensar em situação de alerta para os funcionários da Coelce de Juazeiro do Norte, uma vez que, revelando altos níveis de despersonalização emocional, devem apresentar também sintomatologia associada: sentimentos de frieza com os que estão à sua volta, como colegas de trabalho, superiores e familiares. Quanto à reduzida realização profissional, apesar de serem poucos os indivíduos que a revelaram, podem vir a sentirem falta de motivação e insatisfação com o trabalho, julgando-se incapazes de cumprir com as demandas de sua função, levando a um comprometimento do trabalho do grupo, segundo nos orienta as considerações de Maslach e Jackson (1981).

Em resumo, observou-se indícios de alerta para a Síndrome de Burnout na amostra estudada, entretanto recomendam-se novos estudos em que possam utilizar um universo maior de sujeitos.

A pressão em alguns ambientes de trabalho atinge níveis preocupantes, prejudica a qualidade de vida dos funcionários e obriga as empresas a adotarem medidas contra o desgaste. Às vezes para desencadear uma irritação, uma pequena espera maior do que de costume já é suficiente. As atitudes 
do colega de trabalho ou superior imediato, dentro de suas atribuições normais, às vezes se tornam tão incômodas que podem fazer surgir o mau humor

As relações sociais, as redes de relações e o apoio social são tópicos atuais da Psicologia, especialmente no que diz respeito às contribuições que esta ciência pode dar ao Bem-Estar e Qualidade de Vida Emocional das pessoas (NERI, 2004). Acreditamos que estudos futuros que utilizem o argumento em favor da idéia de que as relações sociais podem, de várias formas, promover melhores condições de saúde, certamente trarão maiores esclarecimentos sobre a temática da Síndrome de Burnout.

\section{Referências}

ALEVATO, Hilda. Trabalho e Neurose: enfrentando a tortura de um ambiente em crise. Rio de Janeiro: Editora Quartet, 1999.

BENEVIDES-PEREIRA, Ana Maria T. (Org). Burnout: quando o trabalho ameaça o bem-estar do trabalhador. São Paulo: Casa do Psicólogo, 2002.

BRASIL. Decreto n. 3.048/99, Regulamento da Previdência Social em apenso, Anexo II, Grupo V CID-10, item XII, 1999.

CARLOTTO, M.S.. Síndrome de burnout e características e cargos em professores universitários. Revista Psicologia: organizações e trabalho, v.42, n.2, p.145-162, 2004.

CODO, W. e VASQUES-MENEZES, I. Burnout: sofrimento psíquico dos trabalhadores em educação. Cadernos de saúde do trabalhador: trabalhadores em educação, v.14, p.29-48, 2000.

DEJOURS, Christophe. A Loucura do Trabalho - Estudo de Psicopatologia do Trabalho. $5^{\text {a }}$ ed., São Paulo: Cortez Editora - Oboré, 1992, p. 14-25

DE MASI, Domenico. O futuro do trabalho. Rio de Janeiro: Editora José Olympio; Brasília, DF: Editora UnB, 1999.

DOMENICH, Mirella. Síndrome de Burnout. Folha de São Paulo, São Paulo, 30 de junho de 2002, Caderno Empregos, p. 01.

FORMIGA, N. S. Valores humanos e condutas anti-sociais e delitivas em jovens. Revista Psicologia: Teoria e Prática 7 (2), 134-170, 2005.

GIL-MONTE, P. R., \& PEIRÓ, J. M. Desgaste psíquico en el trabajo: El síndrome de quemarse. Madrid: Sínteses, 1997.

LIPP, M. (1984). Stress e suas implicações. Estudos de Psicologia, Campinas, v.1, n.3 e 4, p. 5-19, ago/dez.

MASLACH, C. (1993). Burnout: A multidimensional perspective. Em W.B.Schaufeli, C. Maslach \& T. Marek (Eds.),Professional burnout: Recent developments in theory and research (pp.19-32). New York: Taylor \& Francis. 
MASLACH, C., \& JACKSON, S. E. The measurement of experienced burnout. Journal of Ocuppational Behavior, 2, 99-113, 1981. ( $2^{\text {nd }}$ ed). Maslach Burnout Inventory. Palo Alto, CA: Consulting Psychologist Press, 1986.

MASLACH, C., S.E., JACKSON \& LEITER, M. P. The Maslach Burnout Inventory - Test manual. Palo Alto, CA. Consulting Psycologist Press, 1996.

NERI, A. L. (2004). O que a psicologia tem a oferecer ao estudo e à intervenção no campo do envelhecimento no Brasil, hoje. Em A. L. NERI \& M. S. YASSUDA (Orgs), M. Cachioni (Colab.), Velhice bem-sucedida: Aspectos afetivos e cognitivos (pp.13-27). Campinas: Papirus. ORGANIZAÇÃO MUNDIAL DA SAÚDE. CID-10 Classificação Estatística Internacional de Doenças e Problemas Relacionados à Saúde. 10a rev. São Paulo: Universidade de São Paulo; 1997. vol.1.

PETRAITIS, J.; FLAY, B. R. e MILLER, T. Q. Reviewing theories of adolescent substance use: Organizing pieces in the puzzle. Psychological Bulletin, 117, 67-86, 1995.

RODRIGUES, A. Stress, trabalho e doenças de adaptação. in: Franco, a.c.l. \&Rodrigues, a.1. (1997). Stress e trabalho: guia prático com abordagem psicossomática. São Paulo: Atlas, cap. 2.

RODRIGUES, A. L. e GASPARINI, A. C. L. F. (1992). Uma perspectiva psicossocial em psicossomática: via stress e trabalho, in: Mello Filho, J. de (org.) Psicossomática hoje. Porto Alegre: Artes Médicas, p. 93-107.

SELYE, H. (1959). Stress, a tensão da vida. São Paulo: Ibrasa - Instituição Brasileira de Difusão Cultural.

SILVA, Flávia Pietá Paulo da. Burnout: um desafio à saúde do trabalhador. PSI - Revista de psicologia social e institucional. Londrina, vol. 2, n.01, jun. 2000. Disponível em: <http://2.uel.br/ccb/psicologia/revista/textov2n15.htm>. Acesso em: 10 de jan. 2003

TAMAYO, A.; NICARETTA, M.; RIBEIRO, R. e BARBOSA, L. P. G. Prioridades axiológicas y consumo de drogas. Acta Psiquiátrica y Psicológica de la America Latina, 4, 300-307, 1995.

VOLPATO, Daiane Cristina et al. Burnout: o desgaste dos professores de Maringá. Revista Eletrônica Interação Psy, ano 1, n.1, p.90-101, 2003.

Sobre os Autores:

1. Glauco Valério Pinheiro Andrade. Graduado em Tecnologia da Construção Civil pela Universidade Regional do Cariri - URCA. Especialista em Administração de Marketing Financeira e em Gestão de Energia pela Faculdade Leão Sampaio. Acadêmico do curso de Engenharia de Produção Mecânica pela URCA. E-mail: glaucojzn@gmail.com 
2. Maria Glauciane Lima Eduardo Rocha, Graduada em Ciências Econômicas pela Universidade Regional do cariri - URCA. Especialista em Administração financeira pela URCA e Especialista em Gestão de Energia pela Faculdade Leão Sampaio. Acadêmica de Engenharia de Produção pela URCA.

3. Plínio Pinto Malveira é Acadêmico de medicina pela Universidade Federal do Ceará. E-mail: plinio_malveira@hotmail.com

4. Josefa Janiele Lopes Moreira é Acadêmica de Medicina pela Universidade Federal do Ceará. E-mail: janie-moreira@hotmail.com.

\section{Como citar este artigo (Formato ISO):}

ANDRADE, G.V.P.; ROCHA, M.G.L.E.; MALVEIRA, P.P.; MOREIRA, J.J.L. Sindrome de Burnout em Funcionários de uma Empresa de Eletrificação em Juazeiro do Norte. Id on Line Revista de Psicologia, Fevereiro de 2012, vol.1, n.16, p. 55-68. ISSN 1981-1189. 